\title{
Collaboration and Adaptation: Bridging the Space Between Classroom and Open Learning
}

\author{
Ginny Ratsoy \\ Thompson Rivers University
}

This essay draws on a case study and provides strategies for closer collaboration to enhance mutual understanding between face-to-face and open learning. The ways that students and faculty benefit from the team approach used in open learning course creation are outlined. Practical methods of adapting group work and other learner-centred classroom pedagogies to the print medium are also examined.

\section{Introduction}

$\mathrm{E}$ nrollment in open learning courses has seen an unprecedented rise over the last few decades. Formerly limited to a few specialized universities, its providers now number in the thousands worldwide (Calder, 1999). Registration in the Canadian Virtual University, an association of accredited universities specializing in online and distance education, has risen yearly by $10 \%$ since the consortium was created in 2000 so that, by 2006, it boasted 150,000 course registrations (Johnson, 2008). However, relatively few Canadian professors have more than passing familiarity with the model. Furthermore, teaching faculty frequently have deep reservations about open learning (Guri-Rosenblit, 1999). My own concerns were largely pedagogical (although, admittedly, territoriality and unfamiliarity played a role). As an initially reluctant writer of a first-year course on Indig- enous literatures in Canada, I suspected my beliefs in Jerome Bruner's (1996) "mutual learning cultures," in which the teacher is "an enabler" (p. xv) and critical pedagogy's emphasis on the humanistic elements of education (Fobes, 2005), were incompatible with the world of distance education. Particularly in a print-based course (where a television, telephone, and DVD player are the only electronic media a student could be presumed to access), designing such curriculum seemed contradictory to the theories and praxis I have embraced over three decades.

Two familiar models made open learning less alien. The traditional European model of independent study, which has been likened to distance education (Annand, 2007), typically has fewer class contact hours and assignments than the Canadian model, and pays less attention to students' extracur- 
ricular activities (Guri-Rosenblit, 1999). It, therefore, requires of students considerable self-motivation and de-emphasizes the social aspect of education. The nexus between open learning and service learning which provides students with hands-on experience working with community organizations - may be less apparent. However, Annand (2007) also observes that distance (and, by extension, open) learning removes temporal and spatial constraints. Similarly, my students, who are enrolled in the stand-alone service learning model, can compact their placement or schedule their time around other activities, and sometimes work out of their homes, always moving beyond the four walls of a classroom. In sum, the traditional European model, service learning, and print-based open learning are connected by the special demands they place on, and the flexibility they afford, the learner.

Seeing open learning in this light, I accepted the position of course writer, from which I emerged with great respect for the team-writing model. As we worked to create an introduction to the themes, genres, terminology, and disciplinary approaches of literature, our collaboration netted assorted strategies - most adaptable to other disciplines - that enable and engage while respecting course flexibility and student independence. This paper presents a case study model to demonstrate that classroom practises can be adapted to open learning curriculum, and that the open learning team approach to course writing provides a model for face-to-face course development.

\section{Course Writing: The Team Approach}

The team approach not only keeps the course development on task, but it also affords stringent peer review beneficial to the quality of the product and the writer's scholarly development. The team's consultants (with teaching experience in open learning), advisor, and manager scrutinized my writing from theoretical and practical perspectives. If the team approach lessens the possibility of subjectivity (Annand, 2007), we were a model of objectivity.

After the course plan was written collabora- tively, each team member sequentially provided extensive comments, suggestions, and practical observations on each subsequent unit I drafted. I then revised and submitted 'finals' which were further scrutinized and modified.

In the non-face-to-face situation, the challenge of satisfying all participants was ongoing and, because our communication was largely in writing, we received an exceedingly germane lesson in the necessity of thorough and precise expression. Patience, diligence, and compromise are required in the production of a course package that satisfies participants with diverse pedagogical philosophies and experiences as well as engrosses and challenges students.

\section{Course Commentary}

The course commentary is the curriculum team's discussion and analysis of syllabus material. Its classroom equivalent is lecture and discussion. Although it is a tall order to replace the lecture/discussion when communication is fixed, one-way, and to an unknown audience, many techniques that are standard for face-to-face lecturing can be incorporated into the commentary. First- and second-person pronouns, appropriate humour (see Strean, 2008), relevant questions, (see O’Beirne-Ryan, 2008), analogy, and personal anecdote, for example, can reveal the writer's personality, be inclusive, and in other ways, bridge gaps created by distance.

The collaborative nature of course creation allows for an additional approach to bridge distance and model the discourse of academic disciplines. Throughout the course, students are aware of the presence of the creative team. Eschewing the single voice of authority, we introduce ourselves early and use our numbers to illustrate the subjectivity of literary interpretation by providing supplementary or even contradictory analyses: one consultant challenged my analysis of a chapter in a novel, and the other consultant disagreed with my responses to a poem, and we included both responses. These exchanges exemplify disciplinary complexity and mimic classroom discussion. Rather than an omniscient presence dominating, a lively discourse occurs - a 
strategy that can be modified for most subjects.

Sharing aspects of processes involved in course creation can further engage students. Most notably, we provide background to our decision on course naming. This approach can also reveal rationale - important for the students and their instructors.

Visual illustrations - simple or complex - acknowledge different learning styles, break up the print commentary, and give the course a human face. Properly explicated and integrated into the commentary, photographs of each author and production shots from each play studied, for example, add dimension.

Video components, a staple of open learning packages, should be enhancing and integral, rather than supplemental, to the course content; they should also transcend the 'talking heads' approach. Short clips, interspersed throughout the course and incorporated into the written commentary, are most effective. Our advisor's clips reinforce course concepts, but also augment the written commentary by, for example, providing students with the experience of hearing languages used in some of the required readings.

Face-to-face interaction can be emulated through engaged and engaging voices in the commentary; varied print and electronic material can accommodate diverse learning styles; and the communal focus of the commentary can model disciplinary discourse and significantly enhance learner involvement.

\section{Course Materials}

Selection of appropriate, engaging course materials is particularly important in open and distance learning, as Guri-Rosenblit (1999) reminds us, "the venia legendi (the right to teach) is vested in the study materials rather than in the individual lecturer" (p. 25). Moreover, the use of the syllabus materials should be tailored to the open mode.

Although secondary sources may be used infrequently, if at all, in a first-year literature classroom, we theorized that requiring the students to read a considerable number of them is conducive to enhanced connection, as well as pedagogically im- portant. In addition to developing critical thinking faculties and reading comprehension, this activity provides concrete research examples and exposes students to a variety of perspectives, thereby illustrating the subjectivity of literary response and encouraging essays that go beyond regurgitation of the commentary - another foundational pedagogy easily modified for other disciplines.

The secondary sources were selected to introduce students to diverse disciplinary writing modes - from conventional academic discourse through informal dialogue and personal narrative and journalistic work. Thus, students are exposed to the variety of voices they will encounter throughout their studies - in whatever discipline.

Moreover, materials considered as reference or recommended reading in face-to-face learning may assume greater importance in open education. While the equivalent to the English literary handbook is likely a feature of first-year courses in many disciplines, we integrated it to a greater extent than we would in the face-to-face situation: it was repeatedly referred to in the commentary and incorporated into activities and assignments. The preface to a required anthology forms the basis for a writing assignment because it is dialogic and therefore introduces students to a distinct form of written discourse, as well as emulating the orality that is the origin of some syllabus material.

Course writers should also consider, where applicable, including first-hand accounts that reveal the process behind the material studied. In our course, written and audio-taped accounts of the authors' own insights into their work reveal the genesis of the work of literature and thereby personalize it; they also simulate the guest speaker of the traditional classroom. Creativity is requisite in selecting relevant materials and customizing their use to accomplish pedagogical objectives and promote engagement.

\section{Course Activities}

Course activities function as the equivalent to homework, but they can also simulate classroom activities. If they are clearly delineated, varied, and imaginative, 
students are inspired to complete them.

While some of our course activities are apparently standard in open education literature courses, such as keeping a journal and writing responses to questions - pedagogically sound activities in virtually all disciplines - we incorporated more of these activities than is usual. Further, practicalities usually result in open-ended (affective response) questions not requiring tutor input. These "low stake" questions make the student an expert (O'Beirne-Ryan, 2008 , p. 4) and demonstrate the value of varied responses to subjective situations. However, we also posed higher-order questions, which, although they required our carefully crafting answers for students to consult, we deemed essential in a foundational course where critical thinking skills are emphasized.

More extensive activities are also included. For example, composing reference glossaries with space left to add examples from the syllabus requires students to synthesize previous knowledge with commentary and handbook information. Easily adaptable to most introductory courses with discipline-specific vocabulary, this activity, as our commentary emphasizes, reinforces reading and equips the students with a handy guide for subsequent courses.

Adaptation of classroom group activities can also enhance learning. We modified an activity from a how-to guide for face-to-face classrooms that emphasizes the writing process and group work (Bean, 1996). Following a template, students compose a character analysis in poetic form that serves as a model for further character study. Role playing, debating, interviewing, and other techniques can also be revised for print packages in many disciplines.

Course packages commonly include audio tapes, but auditory stimulation can occur on another level: the student can provide an oral component. This is a natural fit with a course on Indigenous literatures that includes units on poetry and drama, but oral activities can also be effective praxis in other disciplines. The student is active - participating - and (whether speaking to a recording device, an audience, or as a solitary activity) experiencing a break from the written text, receiving similar stimulation to students in group activity. To empower and personalize, we discuss Thomas King's (1997) belief that read- ing a story aloud makes the speaker a storyteller - a creator, rather than a mere conveyer. Activities can underscore course objectives and, if they are imaginative, simulate an active classroom.

\section{Conclusions and Recommendations}

Despite their differences, the realms of oral- and print-based delivery can find common ground in their fundamental objective: to facilitate learning. A positive step toward bridging the space is the recognition by all parties of this commonality and a willingness to learn from alternative modes of delivery.

I strongly recommend our mixture of educational experiences be used in preparing distance learning packages - whether introductory or advanced. The exercise engenders cooperation - not to mention mutual awareness and substantial reflection - that is beneficial to all participants in teaching and learning.

Experience with both modes engenders awareness of the strengths of each. The rigour inherent in the collaborative preparation of open learning courses may well result in stronger course content, as Gilles Paquette, Canadian Research Chair in Tele-Learning Cognitive Engineering at Téleq, the distance arm of the Université du Québec, asserts (Johnson, 2008). Unless traditional courses are team taught, collaboration tends to be minimal; yet, classroom educators and their students would be well served by the team approach. Reciprocally, the interactive qualities of the conventional classroom can be adapted to the open learning package. The course writer has a responsibility to be familiar with and attempt to incorporate theories of learning that challenge and engage. When the right to teach is invested in the course package (Guri-Rosenblit, 1999) it becomes, to use Bruner's (1996) terminology, the enabler.

More cooperation between the two modes of knowledge delivery is both ideal and practical. As many countries have difficulty meeting the proliferating demand for university-educated students (Annand, 2006) and open and distance courses continue to increase nationally and globally, bridging the 
space between face-to-face and open delivery modes becomes imperative. Educators in each 'world' have much to share.

\section{References}

Annand, D. (2007). Re-organizing universities for the information age. International Review of Research in Open and Distance Learning, 8(3). Retrieved from http://www.irrodl.org/index. $\mathrm{php} /$ irrodl/article/view/372

Bean, J.C. (1996). Engaging ideas: The professor's guide to integrating writing, critical thinking, and active learning in the classroom. San Francisco: Jossey-Bass.

Bruner, J. (1996). The culture of education. Cambridge, Mass.: Harvard UP.

Calder, J. (1999). Beauty lies in the eye of the beholder. International Review of Research in Open and Distance Learning, 1(1). (2000). Retrieved from http://www.irrodl.org/index. php/irrodl/article/view/6/26.

Fobes, C. (2005) Taking a critical pedagogical look at travel-study abroad: 'A classroom with a view' in Cusco, Peru. Teaching Sociology, 33, 181194.

Guri-Rosenblit, S. (1999). Distance and campus universities: Tensions and interactions, a comparative study of five countries. Oxford: Pergamon.

Johnson, T. (2008). Learning long distance. University Affairs, 49(4), 8-15.

King, T. (1997). Godzilla vs. post-colonial. In A. Heble, D. Palmateer Pennee, \& J.R. Struthers (Eds.), New Contexts of Canadian Criticism. Peterborough: Broadview Press.

O'Beirne-Ryan, A. (2008). Question me an answer: Re-awakening the art of inquiry in post-sec- ondary science education. Collected Essays on Teaching and Learning, 1(1), 1-7.

Strean, W.B. (2008). Evolving toward laughter in learning. Collected Essays on Learning and Teaching, 1(1), 75-79.

\section{Biography}

Ginny Ratsoy is an Assistant Professor of English at Thompson Rivers University in British Columbia, where she teaches Canadian and Aboriginal Literatures and Canadian Studies. Her scholarly publications are in the areas of British Columbian drama, contemporary Canadian literature, and non-traditional teaching pedagogies. 